\title{
Emission Spectroscopy of Pulsed Power Microplasma for Atmospheric Pollution Control
}

\author{
Kazuo Shimizu, Member, IEEE, Tatsuya Ishii, and Marius Blajan, Member, IEEE
}

\begin{abstract}
Pollution of the atmosphere from various sources, including factories and automobiles, is a serious problem worldwide and should be controlled and reduced. Nonthermal plasma is studied by various groups and has been applied for exhaust gas treatment and indoor air purification. Microplasma, which is atmospheric pressure nothermal plasma, has recently been studied by many researchers. Although nonthermal-plasma diagnosis by emission spectroscopy has been applied by many authors, the mechanisms are not sufficiently understood. In this paper, the diagnosis of the microplasma discharge in $\mathrm{N}_{2}$ gas and $\mathrm{N}_{2} / \mathrm{NO}$ gas mixture are presented. An experimental Marx generator with MOSFET switches was used to generate pulsed output voltages of up to $-1.8 \mathrm{kV}$. Emission spectra were observed by a spectrometer with intensified charge-coupled device camera and a photomultiplier tube. The formation of radicals was confirmed by NO- $\gamma$ band, $\mathrm{N}_{2}$ second positive band, and $\mathrm{N}_{2}^{+}$first negative system. Time evolution of light emission that is measured by the photomultiplier tube showed differences between the $\mathrm{NO}-\gamma$ band and the $\mathrm{N}_{2}$ second positive band. This condition is suggested to be the result of different light emission mechanisms; the $\mathbf{N}_{2}$ second positive band is excited by direct electron impact, and the NO- $\gamma$ band is excited by collisions of $\mathrm{N}_{2}$ metastables.
\end{abstract}

Index Terms-Emission spectroscopy, Marx generator, microplasma, pulsed power.

\section{INTRODUCTION}

$\mathbf{N}$ ONTHERMAL plasma is used in applications of cleaning the exhaust gases from various sources such as factories or automobiles [1]-[7]. The term microplasma is typically used to refer to discharges with dimensions that range from a few micrometers up to a few millimeters. The voltage that is required to ignite a discharge, i.e., the breakdown voltage, depends on the product of pressure $p$ and discharge gap $d$, which is also known as the Paschen curve. At atmospheric pressure, the breakdown voltage can be kept low if the discharge gap is below $1 \mathrm{~mm}$.

Paper 2009-EPC-259.R1, presented at the 2009 Joint Conference on Electrostatics, Boston, MA, June 16-18, and approved for publication in the IEEE TRANSACTIONS ON INDUSTRY APPLICATIONS by the Electrostatic Processes Committee of the IEEE Industry Applications Society. Manuscript submitted for review July 27, 2009 and released for publication October 22, 2009. First published March 22, 2010; current version published May 19, 2010.

K. Shimizu is with the Innovation and Joint Research Center, Shizuoka University, Hamamatsu 432-8561, Japan (e-mail: shimizu@ cjr.shizuoka.ac.jp).

T. Ishii was with Shizuoka University, Hamamatsu 432-8561, Japan. He is now with Ricoh Company, Tokyo 104-8222, Japan (e-mail: lynx9991@ gmail.com)

M. Blajan is with Shizuoka University, Hamamatsu 432-8011, Japan (e-mail: blajanmarius@yahoo.com).

Color versions of one or more of the figures in this paper are available online at http://ieeexplore.iee.org.

Digital Object Identifier 10.1109/TIA.2010.2044968

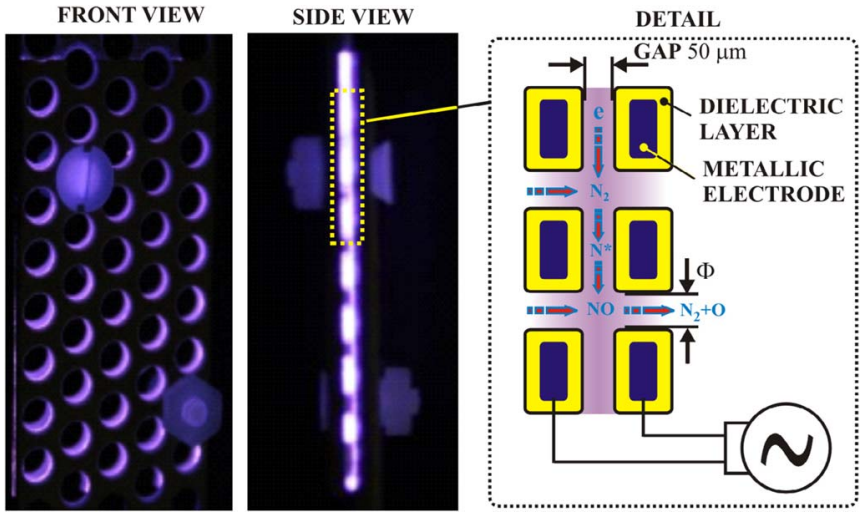

Fig. 1. Schematic of the microplasma electrodes $(40 \mathrm{~mm} \times 20 \mathrm{~mm}$, hole size $2.5 \mathrm{~mm})$. The pressure loss between the electrodes is very small $\left(5 \mathrm{~mm} \mathrm{H}_{2} \mathrm{O}\right.$ at a gas flow rate of $5 \mathrm{~L} / \mathrm{min}$ ).

The typical operating parameters of microplasmas (pressures up to and exceeding $1 \mathrm{~atm}$ and discharge gaps below $1 \mathrm{~mm}$ ) correspond to $p d$ values similar to those for large-volume lowpressure plasmas but with much higher energy densities [8], [9]. The microplasma in this paper is a dielectric barrier discharge (DBD) with a relatively narrow discharge gap of less than $100 \mu \mathrm{m}$. It is generated at relatively low discharge voltages, and the reactor has small dimensions and requires only smallsize power supplies. Most of the microplasma research has been application driven such as air treatment, NOx removal, or sterilization [8]-[11]. Therefore, the fundamental phenomena of microplasma, such as electron energy and generation of radicals, are not fully understood.

The aim of this paper is to analyze the characteristics of microplasma generated by a pulsed power supply by using emission spectroscopy. The pulsed power supply consists of an experimental Marx generator that uses MOSFET switches.

In addition, the ozone generation was analyzed by using pulsed power supply and high-frequency $(25 \mathrm{kHz})$ ac voltage. The gases used in experiments were $\mathrm{N}_{2}, \mathrm{NO} / \mathrm{N}_{2}$ gas mixture, and air. Emission spectroscopy analysis of microplasma was performed with an intensified charge-coupled device (ICCD) camera and a spectrometer, and the time evolution of microplasma discharge was observed by a photomultiplier tube.

\section{Generation of Microplasma}

Fig. 1 shows a schematic image of the electrodes used in the experiments. The microplasma electrodes are from stainless steel covered with dielectric materials. 


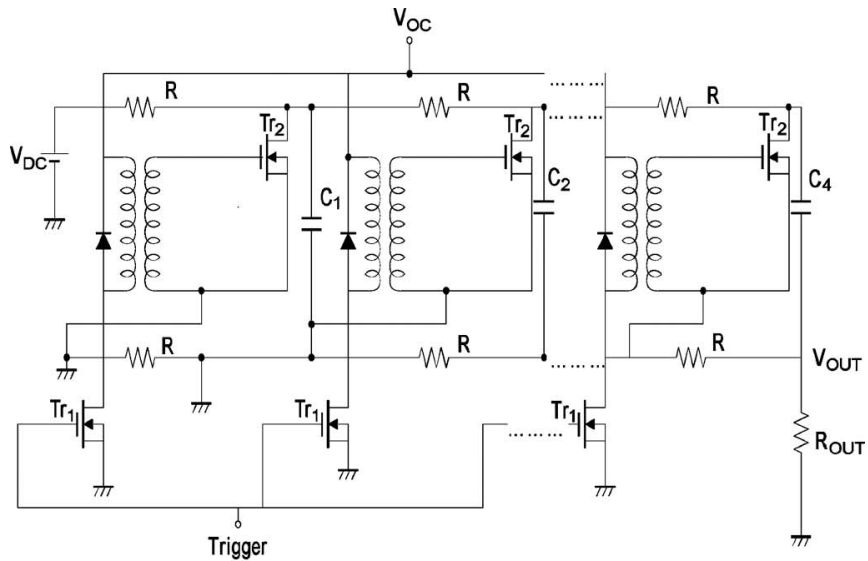

(a)

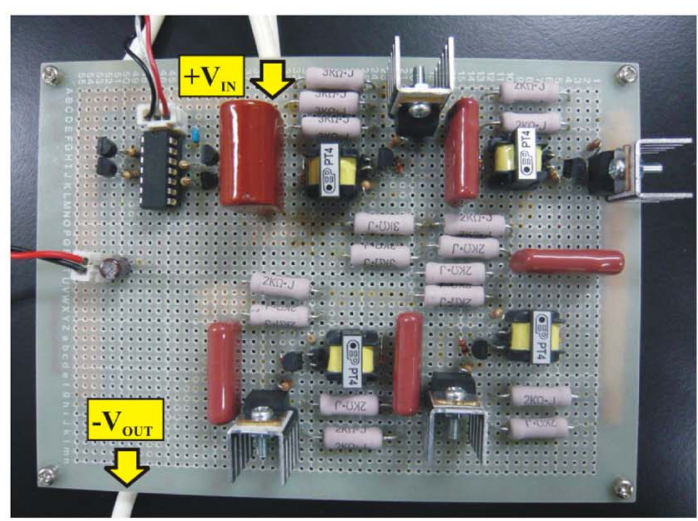

(b)

Fig. 2. (a) Schematic of an experimental Marx generator with MOSFET switches. (b) Image of a Marx generator circuit.

The electrodes are faced together with discharge gaps of $0 \mu \mathrm{m}$ and $50 \mu \mathrm{m}$, respectively. Due to the asperities of the dielectric layer, between electrodes are very small discharge gaps, even at $0 \mu \mathrm{m}$, although they are faced together without a spacer. Thus, microplasma occurs in these small discharge gaps and around the electrodes holes. The discharge gap is small compared to that of other silent discharges; therefore, nonthermal plasma occurs at about a discharge voltage of $1 \mathrm{kV}$.

\section{MARX GENERATOR}

The use of pulsed power in various applications such as NOx removal or biomedical applications is advantageous because of the low cost of equipment and insignificant heating.

Pulsed atmospheric plasma has a higher electrical efficiency than the sinusoidal plasma due to the long-time plasma-off period, which reduces power consumption.

The microplasma was generated by applying pulse voltage, using a Marx generator as power supply. The experimental circuit is presented in Fig. 2. An experimental Marx generator generates negative pulses triggered by semiconductor switches.

When the metal oxide semiconductor field-effect transistor (MOSFET) switches are opened, the capacitors linked in parallel connection are charged at a given voltage $V$.

By turning on the MOSFET switches, the capacitors discharge in a series connection, and the voltage is the input

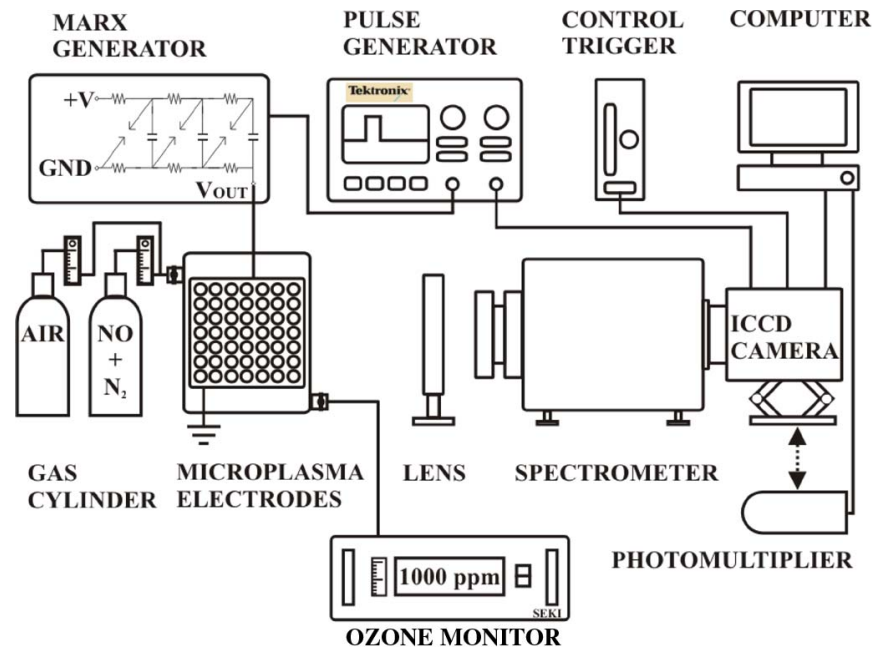

Fig. 3. Experimental setup for observing emission from microplasma electrodes.

voltage $V$ multiplied by the number of capacitors from the circuit.

The experimental circuit consists of four capacitors. The charge voltage $V$ was set to $500 \mathrm{~V}$, and a tail resistor Rout $=$ $2 \mathrm{k} \Omega$ was used to generate a pulse frequency of $4 \mathrm{kHz}$.

\section{EXPERIMENTAL SETUP}

The experimental setup is presented in Fig. 3. The emission spectrum from the microplasma reactor was measured by an ICCD camera (Ryoushi-giken, SMCP-ICCD 1024 HAMNDS/UV), a spectrometer (Ryoushi-giken, VIS 351), and a photomultiplier tube (Hamamatsu, R 3896). A pulse generator (Tektronix, AFG 3021B) was used to trigger the experimental Marx generator and the ICCD camera. Emission spectra were visualized and recorded through software on the computer that is linked to the ICCD camera.

Emission spectroscopy experiments were performed with microplasma electrodes with a size of $40 \mathrm{~mm} \times 20 \mathrm{~mm}$ and an aperture ratio of $36 \%$. The aperture ratio represents the percentage of holes area from the total area of electrode. Electrodes were placed inside a box through which the gas was flowed. The discharge gap between the electrodes was set to $50 \mu \mathrm{m}$, with a dielectric spacer. The plasma luminescence was detected from the side part of the electrodes through a quartz window. Thus, the observed microplasma area is $40 \mathrm{~mm} \times 50 \mu \mathrm{m}$.

Ozone and NOx generation was confirmed with different microplasma electrodes with a diameter of $45 \mathrm{~mm}$ and an aperture ratio of $8.7 \%$.

The discharge gap between the electrodes was set to $0 \mu \mathrm{m}$. Ozone concentrations were measured with an ozone monitor (Ebara Jitsugyo, EG-2001B). NOx concentrations were measured by using a NOx monitor (Shimadzu, NOA-7000A).

The discharge voltage and its corresponding discharge current were measured by a high-voltage probe (Tektronix, P6015), an ac current transformer (Tektronix, P6021), and a digital oscilloscope (Tektronix, TDS 2014B).

The composition of the discharge gas in the experiments was pure nitrogen and NO $1000 \mathrm{ppm}, \mathrm{N}_{2}$ balance for the emission 


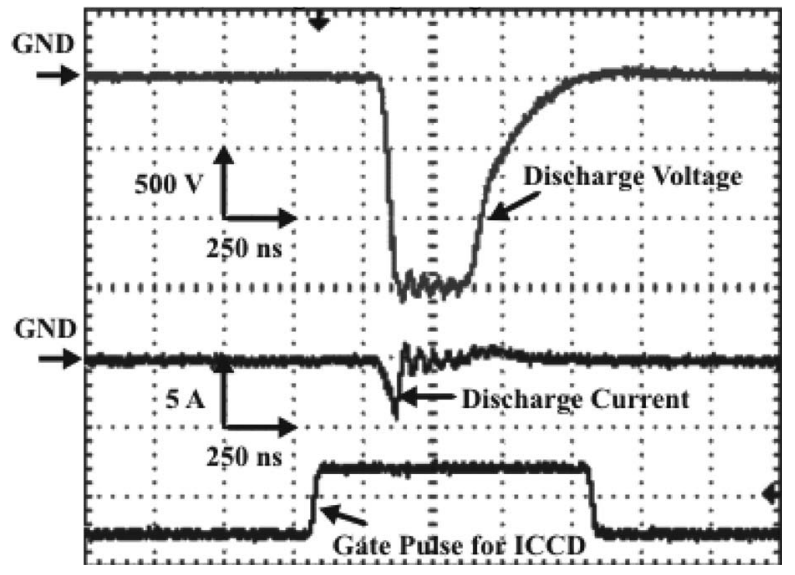

Fig. 4. Example of discharge voltage, its corresponding discharge current, and gate pulse for the ICCD camera (250 ns/div).

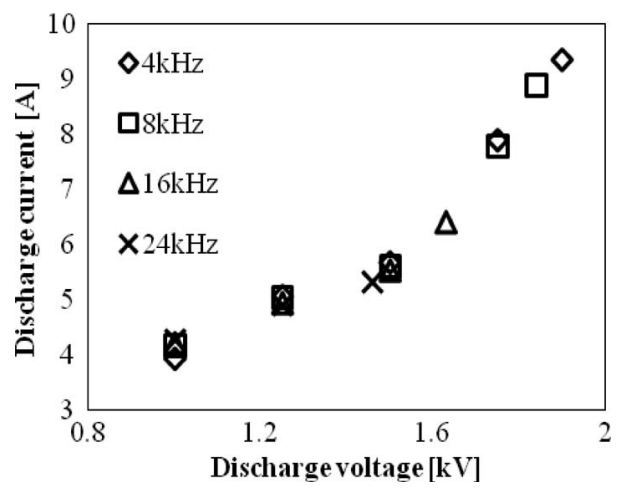

Fig. 5. Characteristics of peaks values of discharge voltages versus peaks values of discharge current of an experimental Marx generator.

spectroscopy experiments, and air for the generation of ozone. The gas flow rate was set at $2 \mathrm{~L} / \mathrm{min}$.

Fig. 4 shows the waveforms of discharge voltage, discharge current, and gate pulse for the ICCD camera. The ICCD camera was turned on $1 \mu \mathrm{s}$, which started when the gate signal voltage was input.

\section{Characteristics of Microplasma}

Fig. 5 shows the characteristics of peak values of discharge voltage versus peak values of discharge current of an experimental Marx generator for various frequencies from $4 \mathrm{kHz}$ to $24 \mathrm{kHz}$. The measured discharge current also has a capacitive component. Discharge currents increase with the increase in discharge voltages for all the frequencies. A discharge current does not depend on frequency.

It was observed that almost the same discharge currents are obtained with the same discharge voltages at different frequencies.

Each value of the discharge currents was measured for the individual pulse and represents the peak value. Thus, for the same discharge voltage, the value of the discharge current is the same, regardless of the frequency value. The points on the characteristics represent the average value of five measurements.

The microplasma onset voltage is considered to be the discharge voltage that corresponds to the beginning of emission

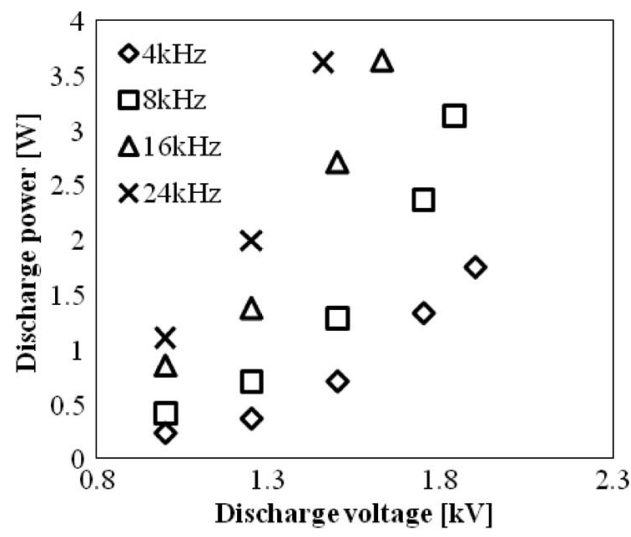

Fig. 6. Characteristics of discharge voltage versus discharge power of an experimental Marx generator.

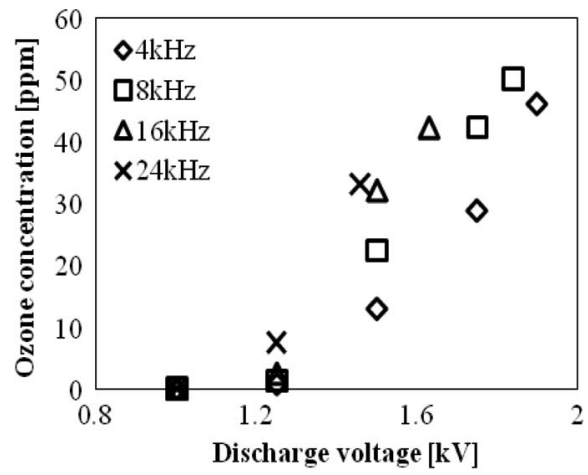

Fig. 7. Characteristics of ozone generation versus discharge voltage.

measured by the ICCD camera. Very small peaks that correspond to the $\mathrm{N}_{2}$ second positive system band were observed, which started with the discharge voltage of $-1.2 \mathrm{kV}$.

Fig. 6 shows the characteristics of discharge voltages versus discharge power of an experimental Marx generator. The discharge power was calculated from the measured energy represented by the area of the respective discharge voltage multiplied by the discharge current. The discharge power increased with the increase in frequency. The highest discharge power of $3.5 \mathrm{~W}$ was obtained at $16 \mathrm{kHz}$.

\section{Ozone and NOx Generation by Marx Generator}

Fig. 7 shows the characteristics of ozone generation by using an experimental Marx generator. The air flow rate was set to $5 \mathrm{~L} / \mathrm{min}$. Ozone generation was observed when the discharge voltage was higher than $-1.2 \mathrm{kV}$. Characteristics of ozone generation increase as the frequency goes up. The Marx generator in our experiments has limitations of functioning at high frequencies as the voltage increases. Thus, the maximum ozone generation value was $51 \mathrm{ppm}$ at $8 \mathrm{kHz}$.

Fig. 8 shows the comparison of ozone generation between an experimental Marx generator and a neon transformer. The frequency of the neon transformer was set to $25 \mathrm{kHz}$. When the frequency of the discharge voltage was low, an increase in ozone concentration was observed almost linearly. Generation 


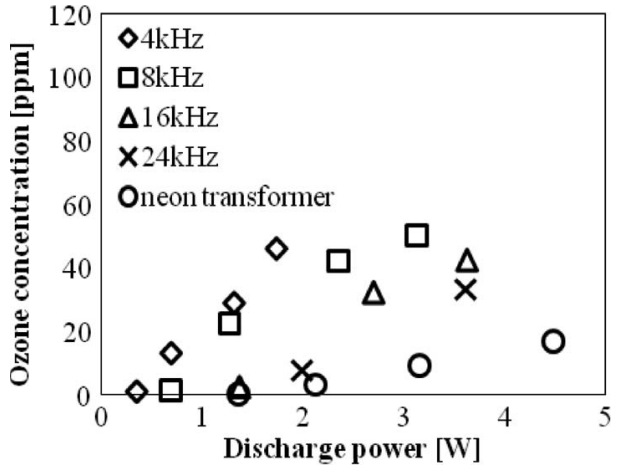

Fig. 8. Characteristics of ozone generation versus discharge power. An ac neon transformer $(25 \mathrm{kHz})$ was used to compare the efficiency of generating ozone.

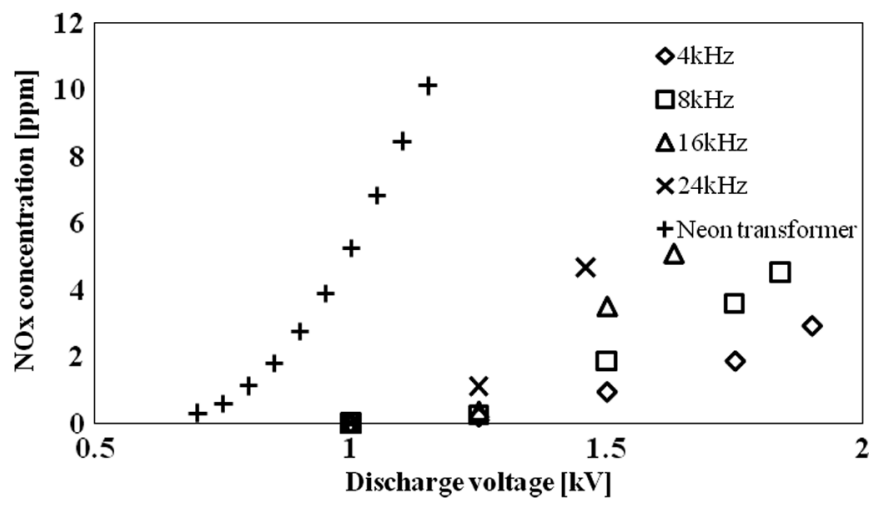

Fig. 9. Characteristics of $\mathrm{NO}_{\mathrm{X}}$ generation versus discharge power. An ac neon transformer $(25 \mathrm{kHz})$ was used to compare the generation of $\mathrm{NO}_{\mathrm{X}}$.

of ozone has peaks at certain discharge power and is influenced by the size of the microplasma electrode, gas flow rate, and other factors.

The maximum ozone concentration was about $50 \mathrm{ppm}$ for the experimental Marx generator, and for the AC power source, it was less than $20 \mathrm{ppm}$.

The power measurements for the neon transformer were realized by using the Lissajous figure method. For the pulse power supply, the product between the discharge voltage and the corresponding discharge current was integrated in time by using an oscilloscope. To obtain the discharge power, the measured energy was divided by time.

Based on this result, a Marx generator has higher efficiency for generating ozone. When the ac voltage is applied for discharge, the capacitive current flow results in the loss of energy.

Fig. 9 shows the characteristics of NOx generation versus discharge voltage by a Marx generator and a neon transformer.

NOx generation was observed at $700 \mathrm{~V}$ when the neon transformer was used and at $1.25 \mathrm{kV}$ for the Marx generator. NOx generations of $10 \mathrm{ppm}$ for the neon transformer and $5 \mathrm{ppm}$ for the Marx generator were obtained at $1.1 \mathrm{kV}$ and at $1.7 \mathrm{kV}$, $16 \mathrm{kHz}$, respectively.

Lower values of NOx generation were measured for the pulsed power supply due to the higher electron density in the pulsed microplasma compared with the sinusoidally excited one, which indirectly enhances the gas ionization rate and promotes the reduction reaction of $\mathrm{NO}$ to $\mathrm{N}_{2}$.

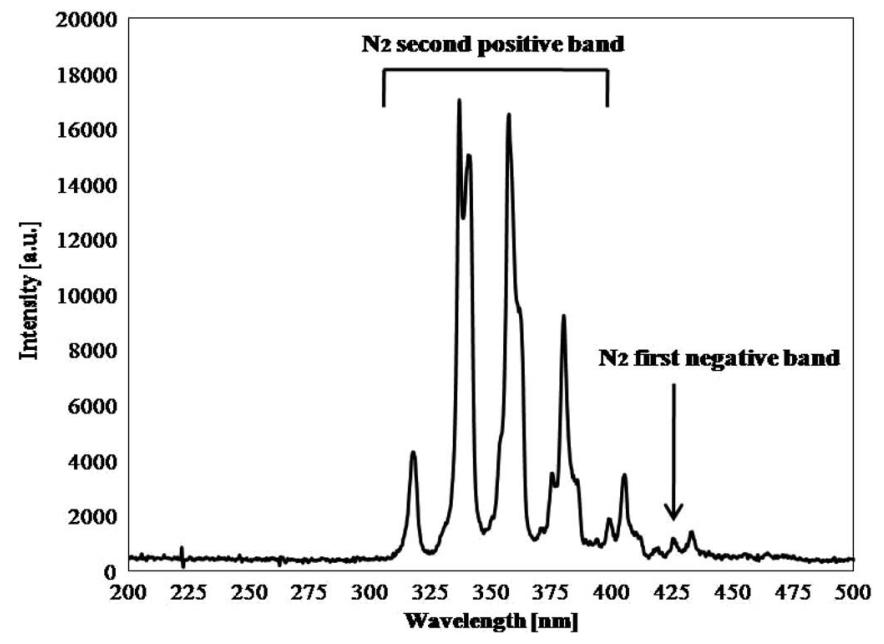

Fig. 10. Emission spectrum of pure nitrogen (with $\mathrm{V}_{\mathrm{D}}=-1.76 \mathrm{kV}, \mathrm{I}_{\mathrm{D}}=$ $-4.6 \mathrm{~A}$, a frequency of $1 \mathrm{kHz}$, and a trigger pulse of $1 \mu \mathrm{s}$ ).

TABLE I

List of Detected Peaks by Emission Spectrometry

\begin{tabular}{|c|c|c|}
\hline $\begin{array}{c}\text { Species } \\
(\text { system) }\end{array}$ & Transition & $\begin{array}{c}\text { Peak Position } \\
(\mathrm{nm})\end{array}$ \\
\hline $\begin{array}{c}\mathrm{N}_{2} \text { second } \\
\text { positive }\end{array}$ & $\mathrm{C}^{3} \Pi \rightarrow \mathrm{B}^{3} \Pi$ & $\begin{array}{c}296 ; 315 ; 337 ; 358 ; \\
376 ; 381 ; 400\end{array}$ \\
\hline $\begin{array}{c}\mathrm{N}_{2}{ }^{+} \text {first } \\
\text { negative }\end{array}$ & $\mathrm{B}^{2} \Sigma_{\mathrm{u}}{ }^{+} \rightarrow \mathrm{X}^{2} \Sigma_{\mathrm{g}}^{+}$ & $391 ; 428$ \\
\hline
\end{tabular}

\section{EMISSION SPECTROSCOPY IN NITROGEN}

Fig. 10 shows the emission spectra of microplasma in nitrogen gas. The $\mathrm{N}_{2}$ second positive band and the $\mathrm{N}_{2}^{+}$first negative band appeared in these spectra ([12]; see Table I). The experiments were performed at $-1.6 \mathrm{kV}$ (with a negative pulse, a rise time of $80 \mathrm{~ns}$, and a width of $530 \mathrm{~ns}$ ) and a corresponding discharge current of $-4.6 \mathrm{~A}$. The ICCD trigger pulse was set to $1 \mu \mathrm{s}$. A negative pulsed voltage was used to generate microplasma.

The camera's shutter opening period of $1 \mu$ s must be synchronized with the microplasma on the period generated by applying a pulse voltage of $530 \mathrm{~ns}$ width. This way, the measured emission spectrum was the result of a single pulse.

The $\mathrm{N}_{2}$ second positive band peak of $337.1 \mathrm{~nm}$ originated in the following electron collisions [12]:

$$
\begin{aligned}
e+\mathrm{N}_{2}\left(\mathrm{X}^{1} \Sigma_{\mathrm{g}}^{+}\right) & \rightarrow \mathrm{N}_{2}\left(\mathrm{C}^{3} \prod_{\mathrm{u}}\right)+e \\
\mathrm{~N}_{2}\left(\mathrm{C}^{3} \prod_{\mathrm{u}}\right) & \rightarrow \mathrm{N}_{2}\left(\mathrm{~B}^{3} \prod_{\mathrm{g}}\right)+\mathrm{h} \nu \text { (second positive) } .
\end{aligned}
$$

Electron collisions energy at the second positive band is at least $11 \mathrm{eV}$ (see Table II) [13], [14]. Therefore, these electrons have energy levels of more than $11 \mathrm{eV}$ in the microplasma.

Fig. 11 shows the time evolution of the $\mathrm{N}_{2}$ second positive band. Emission appeared at the rising and falling parts of 
TABLE II

Rate Constant of $\mathrm{N}_{2}$ Second Positive Band [13]

\begin{tabular}{|c|c|}
\hline Reaction & Rate constant \\
\hline $\begin{array}{c}\mathrm{e}+\mathrm{N}_{2}\left(\mathrm{X}^{1} \Sigma \mathrm{g}^{+}\right) \rightarrow \mathrm{N}_{2}\left(\mathrm{C}^{3} \Pi_{\mathrm{u}}\right)+\mathrm{e} \\
\mathrm{E}_{0}=11 \mathrm{eV}\end{array}$ & $\mathrm{f}(\mathrm{E} / \mathrm{N})$ \\
\hline $\mathrm{N}_{2}\left(\mathrm{C}^{3} \Pi_{\mathrm{u}}\right) \rightarrow \mathrm{N}_{2}\left(\mathrm{~B}^{3} \Pi_{\mathrm{g}}\right)+\mathrm{h} v$ & $3 \times 10^{7} \mathrm{~s}^{-1}[14]$ \\
\hline
\end{tabular}

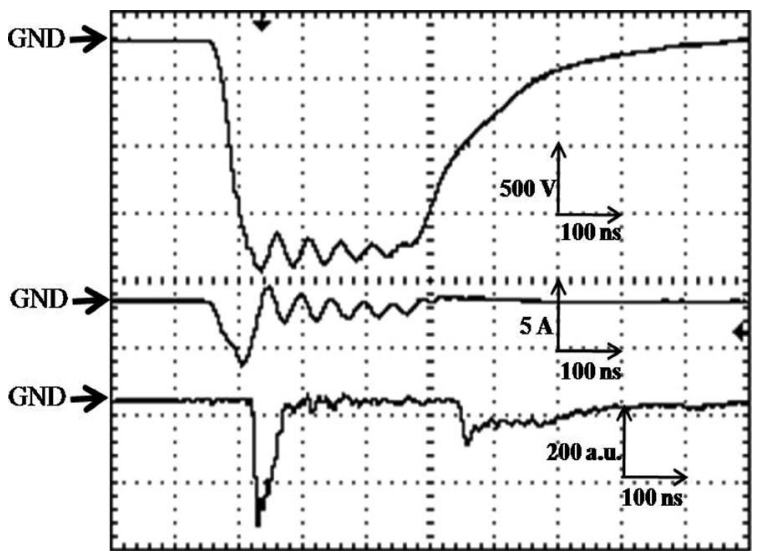

Fig. 11. Waveforms of discharge voltage, discharge current, and emission signal of the microplasma $\left(\mathrm{N}_{2}\right.$ second positive band, $\left.337.1 \mathrm{~nm}\right)$.

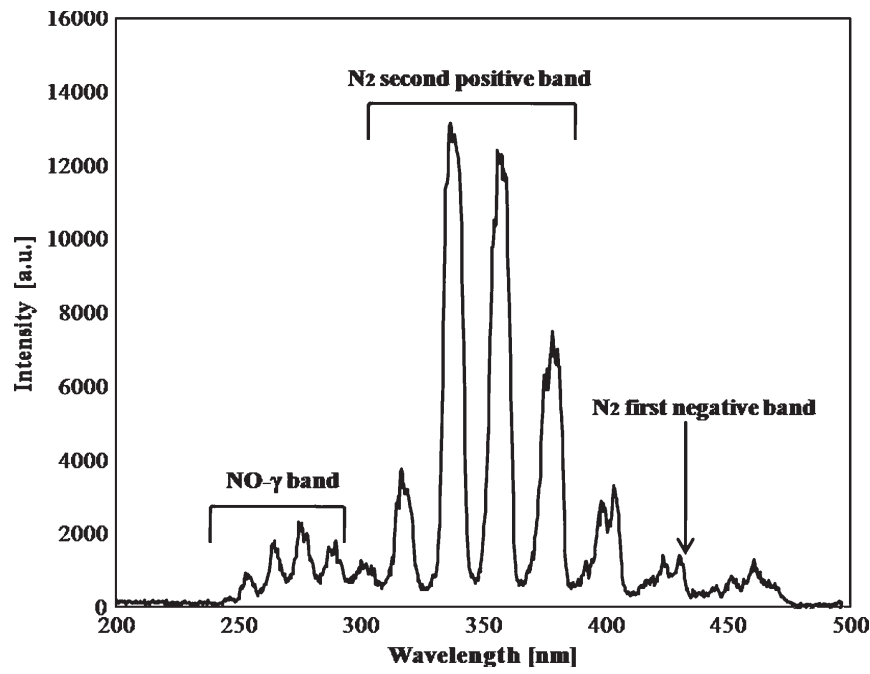

Fig. 12. Emission spectrum of the $\mathrm{NO} / \mathrm{N}_{2}$ mixture (with $\mathrm{V}_{\mathrm{D}}=-1.76 \mathrm{kV}$, $\mathrm{I}_{\mathrm{D}}=-4.6 \mathrm{~A}$, a frequency of $1 \mathrm{kHz}$, and a trigger pulse of $\left.1 \mu \mathrm{s}\right)$.

the discharge voltage. The emission time was about $50 \mathrm{~ns}$. Emission of the $\mathrm{N}_{2}$ second positive band was observed by electron collisions. In addition, the $\mathrm{N}_{2}(\mathrm{C})$ lifetime is estimated to be about $37 \mathrm{~ns}$ [15].

The presence of $\mathrm{N}_{2}^{+}$first negative system band $\left(\mathrm{B}^{2} \Sigma_{\mathrm{u}}^{+} \rightarrow\right.$ $\left.\mathrm{X}^{2} \Sigma_{\mathrm{g}}^{+}\right)$in the spectra, with peaks at $391.5 \mathrm{~nm}$ and $428 \mathrm{~nm}$, indicate high-electron temperatures and a high level of nonequilibrium [16].

Energetic electrons initiate dissociations and ionizations that are essential for gas cleaning and can recommend microplasma as a solution for atmospheric pollution control applications.
TABLE III

List of Detected PeaKs By EMission Spectrometry

\begin{tabular}{|c|c|c|}
\hline $\begin{array}{c}\text { Species } \\
(\text { system) }\end{array}$ & Transition & $\begin{array}{c}\text { Peak Position } \\
(\mathrm{nm})\end{array}$ \\
\hline $\begin{array}{c}\mathrm{N}_{2} \text { second } \\
\text { positive }\end{array}$ & $\mathrm{C}^{3} \Pi \rightarrow \mathrm{B}^{3} \Pi$ & $\begin{array}{c}296 ; 315 ; 337.7 ; 357.7 ; \\
375.5 ; 380.5 ; 400\end{array}$ \\
\hline $\begin{array}{c}\mathrm{N}_{2}^{+} \text {first } \\
\text { negative }\end{array}$ & $\mathrm{B}^{2} \Sigma_{\mathrm{u}}{ }^{+} \rightarrow \mathrm{X}^{2} \Sigma_{\mathrm{g}}^{+}$ & 427.8 \\
\hline NO- $\gamma$ band & $\mathrm{A}^{2} \Sigma^{+} \rightarrow \mathrm{X}^{2} \Pi$ & $\begin{array}{c}226.9 ; 237.0 ; 247.9 ; \\
259.6 ; 271.5 ; 285.0\end{array}$ \\
\hline
\end{tabular}

TABLE IV

RATE CONSTANT OF NO- $\gamma$ BAND

\begin{tabular}{|c|c|}
\hline Reaction & Rate constant \\
\hline $\begin{array}{c}\mathrm{N}_{2}(\mathrm{~A})+\mathrm{NO}(\mathrm{X}) \\
\rightarrow \mathrm{N}_{2}(\mathrm{X})+\mathrm{NO}(\mathrm{A})\end{array}$ & $\begin{array}{c}(6.5-7.8) \times 10^{-11} \\
\mathrm{~cm}^{3} \mathrm{~s}^{-1}\end{array}$ \\
\hline $\begin{array}{c}\mathrm{NO}(\mathrm{A}) \rightarrow \\
\mathrm{NO}(\mathrm{X})+ \\
h v(\mathrm{NO}-\gamma \text { band })\end{array}$ & $5 \times 10^{6} \mathrm{~s}^{-1}[18]$ \\
\hline
\end{tabular}

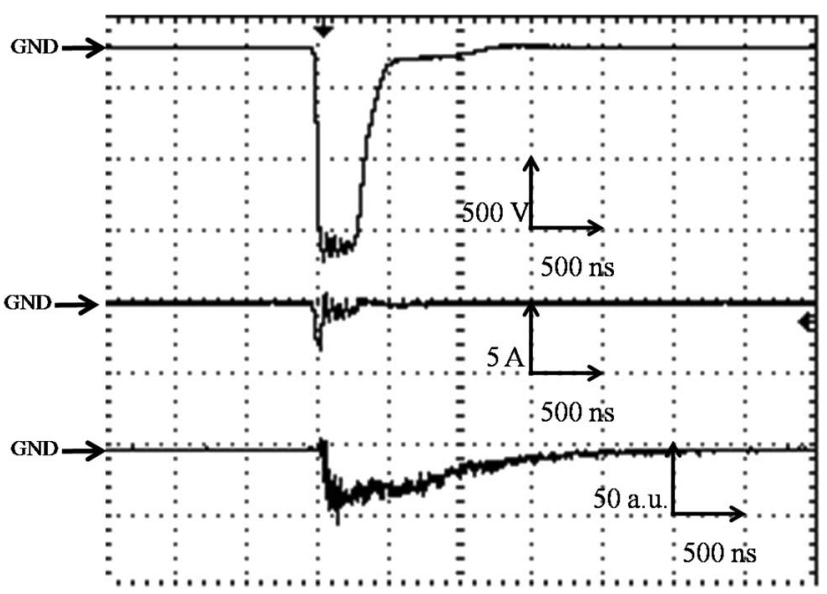

Fig. 13. Waveforms of discharge voltage, discharge current, and emission signal of the microplasma (the NO- $\gamma$ band).

\section{Emission Spectroscopy IN NO/N $\mathrm{N}_{2}$ MiXture}

Fig. 12 shows an example of an emission spectra in $\mathrm{NO} / \mathrm{N}_{2}$ mixture. The NO- $\gamma$ band, the $\mathrm{N}_{2}$ second positive band, and the $\mathrm{N}_{2}^{+}$first negative band were detected (see Table III) [14]. The experiments were performed at $-1.6 \mathrm{kV}$ (with a negative pulse, a rise time of $80 \mathrm{~ns}$, and a width of $530 \mathrm{~ns}$ ) and a corresponding discharge current of $-4.6 \mathrm{~A}$. The ICCD trigger pulse was set to $1 \mu \mathrm{s}$.

The NO- $\gamma$ band originated in the following collisions of the $\mathrm{N}_{2}$ metastable state (see Table IV) [17], [18]:

Excitation

$$
\mathrm{N}_{2}\left(\mathrm{~A}^{3} \Sigma_{\mathrm{u}}^{+}\right)+\mathrm{NO}\left(\mathrm{X}^{2} \prod\right) \rightarrow \mathrm{N}_{2}\left(\mathrm{X}^{2} \Sigma_{\mathrm{g}}\right)+\mathrm{NO}\left(\mathrm{A}^{2} \Sigma^{+}\right)
$$

Radiative transition

$$
\mathrm{NO}\left(\mathrm{A}^{2} \Sigma^{+}\right) \rightarrow \mathrm{NO}\left(\mathrm{X}^{2} \prod\right)+\mathrm{h} \nu(\mathrm{NO}-\gamma \text { band }) .
$$

Fig. 13 shows the time evolution of the NO- $\gamma$ band. Emission appeared when the discharge voltage rises and falls. The emission time was observed about $2 \mu \mathrm{s}$. Because of this phenomenon, the NO- $\gamma$ band causes collisions of the $\mathrm{N}_{2}$ metastable 


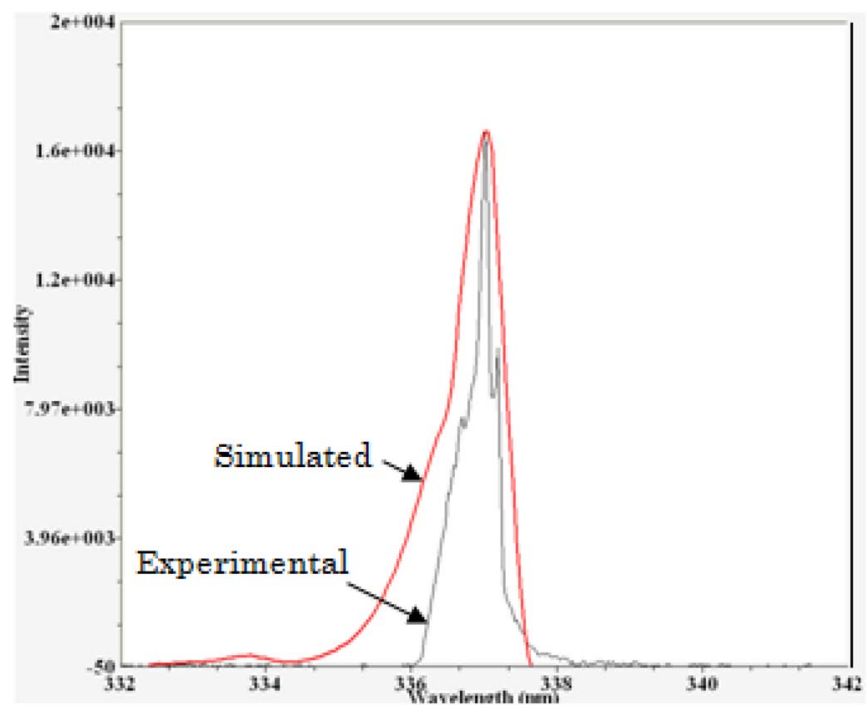

Fig. 14. Measured and simulated optical emission spectra of the nitrogen second positive band system.

TABLE V

Estimated Temperatures of Microplasma in PuRe Nitrogen AT ATMOSPHERIC PRESSURe

\begin{tabular}{|c|c|}
\hline Temperature & Value $(\mathrm{k})$ \\
\hline Electron temperature & 8200 \\
\hline Rotational temperature & 360 \\
\hline Vibrational temperature & 3100 \\
\hline
\end{tabular}

state. The $\mathrm{N}_{2}$ metastable state lifetime is relatively long, with $1.9 \mathrm{~s}$ [15]. The presence of the metastable state $\mathrm{N}_{2}\left(\mathrm{~A}^{3} \Sigma_{\mathrm{u}}^{+}\right)$can be proven by the measurement of the lifetime emission signal of the NO- $\gamma$ band.

\section{Gas Temperature of Microplasma}

Plasma temperature was estimated from the measured emission spectra [19]. Comparison between the calculated curve and the measured value are shown in Fig. 14. By comparing the measured spectrum to the simulated spectrum of the nitrogen second positive band system, it is possible to estimate the rotational and vibrational temperatures. Experiments are carried out under atmospheric pressure; therefore, the rotational temperature can be close to the actual gas temperature.

Table $\mathrm{V}$ shows the calculated temperatures of the microplasma. The estimated rotational temperature and the vibrational temperature of the microplasma show specific values for nonthermal plasma [20].

\section{CONClusion}

The analysis of emission spectra of the microplasma in $\mathrm{NO} / \mathrm{N}_{2}$ mixture has been performed, and the following findings have been observed:

1) Ozone generation by Marx generator was $51 \mathrm{ppm}$ at $8 \mathrm{kHz}$. The Marx generator was more efficient than the neon transformer from the point of the discharge power. Generated NOx values were lower when the Marx Generator was used. The maximal values of $10 \mathrm{ppm}$ for the neon transformer and $5 \mathrm{ppm}$ for the Marx generator were obtained at $1.1 \mathrm{kV}$ and $1.7 \mathrm{kV}, 16 \mathrm{kHz}$, respectively.

2) A negative pulse was applied to microplasma electrode. Emission spectra from the generated microplasma were obtained by an ICCD camera and a spectrometer. $\mathrm{N}_{2}$ second positive band peaks $(337.1 \mathrm{~nm}, 315 \mathrm{~nm}, 357.7 \mathrm{~nm}$, and $375.5 \mathrm{~nm}$ ) and NO- $\gamma$ band peaks $(247.9 \mathrm{~nm}$ and $257.6 \mathrm{~nm}$ ) were observed. In addition, the $\mathrm{N}_{2}^{+}$first negative band peak was confirmed at $427.8 \mathrm{~nm}$.

3) The $\mathrm{N}_{2}$ second positive band appeared after $50 \mathrm{~ns}$. The $\mathrm{N}_{2}$ second positive band is the result of electron collisions. NO- $\gamma$ band peaks appeared after $2 \mu$ s. The NO- $\gamma$ band originated following the collisions of the $\mathrm{N}_{2}$ metastable state.

4) By comparing the measured spectrum to the simulated spectrum of the nitrogen second positive band system, it is possible to estimate the rotational and vibrational temperatures. The estimated rotational temperature $(360 \mathrm{~K})$ and the vibrational temperature $(3100 \mathrm{~K})$ show that the microplasma is a nonthermal plasma.

\section{REFERENCES}

[1] U. Kogelschatz, "Dielectric-barrier discharges: Their history, discharge physics, and industrial applications," Plasma Chem. Plasma Process., vol. 23, no. 1, pp. 1-46, Mar. 2003.

[2] U. Roland, F. Holzer, and F.-D. Kopinke, "Improved oxidation of air pollutants in a nonthermal plasma," Catal. Today, vol. 73 , no. 3/4, pp. 315323, Apr. 2002.

[3] M. Higashi and K. Fujii, "Treatment of exhaust gas from vehicles by discharge plasma reactors," Elect. Eng. Jpn., vol. 120, no. 2, pp. 1-7, Jul. 1998.

[4] C. H. Tsai, Y. F. Wang, H. H. Yang, and C. N. Liao, "Effects of ethylene on NO conversion and product distributions in an rf discharge reactor," $J$. Hazardous Mater., vol. 150, no. 2, pp. 401-407, Jan. 2008.

[5] Q. Yu, H. M. Yang, K. S. Zeng, Z. W. Zhang, and G. Yu, "Simultaneous removal of $\mathrm{NO}$ and $\mathrm{SO}_{2}$ from dry gas stream using nonthermal plasma," J. Environ. Sci., vol. 19, no. 11, pp. 1393-1397, 2007.

[6] S. Sato, K. Hensel, H. Hayashi, K. Takashima, and A. Mizuno, "Honeycomb discharge for diesel exhaust cleaning," J. Electrostat., vol. 67, no. 2/3, pp. 77-83, May 2009.

[7] J. S. Chang, "Recent development of plasma pollution control: Critical review," Sci. Technol. Adv. Mater., vol. 2, no. 3/4, pp. 571-576, Sep. 2001.

[8] F. Iza, G. J. Kim, S. M. Lee, J. K. Lee, J. L. Walsh, Y. T. Zhang, and M. G. Kong, "Microplasmas: Sources, particle kinetics, and biomedical applications," Plasma Process. Polym., vol. 5, no. 4, pp. 322-344, Apr. 2008.

[9] R. Foest, M. Schmidt, and K. Becker, "Microplasmas: An emerging field of low-temperature plasma science and technology," Int. J. Mass Spectrom., vol. 248, no. 3, pp. 87-102, Feb. 2006.

[10] K. Shimizu, T. Sugiyama, and M. Samaratunge, "Study of air pollution control by using microplasma filter," IEEE Trans. Ind. Appl., vol. 44, no. 2, pp. 506-511, Mar./Apr. 2008.

[11] K. Shimizu, M. Yamada, M. Kanamori, and M. Blajan, "Basic study of sterilization at low discharge voltage by using microplasma," in Conf. Rec. IEEE IAS Annu. Meeting, 2008, pp. 1-6.

[12] A. Qayyum, S. Zeb, S. Ali, A. Waheed, and M. Zakaullah, "Optical emission spectroscopy of abnormal glow region in nitrogen plasma," Plasma Chem. Plasma Process., vol. 25, no. 5, pp. 551-564, Oct. 2005.

[13] M. Simek, V. Babicky, M. Clupek, S. DeBenedictis, G. Dilecce, and P. Sunka, "Excitation of $\mathrm{N}_{2}\left(\mathrm{C}^{3} \prod_{11}\right)$ and $\mathrm{NO}\left(\mathrm{A}^{2} \Sigma^{+}\right)$states in a pulsed positive corona discharge in $\mathrm{N}_{2}, \mathrm{~N}_{2}-\mathrm{O}_{2}$ and $\mathrm{N} 2-\mathrm{NO}$ mixtures," J. Phys. D, Appl. Phys., vol. 31, no. 19, pp. 2591-2602, Oct. 1998.

[14] I. A. Kossyi, A. Y. Kostinsky, A. A. Matveyev, and V. P. Silakov, "Kinetic scheme of the nonequilibrium discharge in nitrogen-oxygen mixtures," Plasma Sources Sci. Technol., vol. 1, no. 3, pp. 207-220, Aug. 1992.

[15] A. Lofthus and P. H. Krupenie, "The spectrum of molecular nitrogen," $J$. Phys. Chem. Ref. Data, vol. 6, no. 1, pp. 113-307, Jan. 1977.

[16] Z. Machala, M. Janda, K. Hensel, I. Jedlovsky, L. Lestinska, V. Foltin, V. Martisovits, and M. Morvova, "Emission spectroscopy of atmospheric 
pressure plasmas for biomedical and environmental applications," J. Mol. Spectrosc., vol. 243, no. 2, pp. 194-201, Jun. 2007.

[17] K. Shimizu and T. Oda, "Emission spectrometry for discharge plasma diagnosis," Sci. Technol. Adv. Mater., vol. 2, no. 3/4, pp. 577-585, Sep. 2001.

[18] L. G. Piper, L. M. Cowles, and W. T. Rawlins, "State-to-state excitation of $\mathrm{NO}\left(\mathrm{A}^{2} \Sigma^{+}, \mathrm{v}^{\prime}=0,1,2\right)$ by $\mathrm{N}_{2}\left(\mathrm{~A}^{3} \Sigma_{\mathrm{u}}^{+}, \mathrm{v}^{\prime}=0,1,2\right)$," J. Chem. Phys., vol. 85 , no. 6 , pp. 3369-3378, Sep. 1986.

[19] C. O. Laux, T. G. Spence, C. H. Kruger, and R. N. Zare, "Optical diagnostics of atmospheric pressure air plasmas," Plasma Sources Sci. Technol., vol. 12, no. 2, pp. 125-138, May 2003.

[20] J. L. Walsh and M. G. Kong, "10-ns pulsed atmospheric air plasma for uniform treatment of polymeric surfaces," Appl. Phys. Lett., vol. 91, no. 25 , p. 251 504, Dec. 2007.

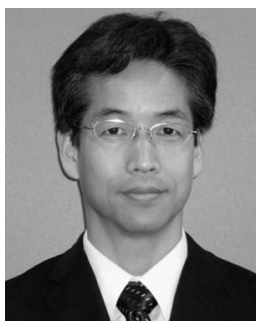

Kazuo Shimizu (S'93-M'00) was born in Hamamatsu, Japan, in 1969. He received the B.S., M.S., and Ph.D. degrees in electrical engineering from Toyohashi University of Technology, Toyohashi, in 1991, 1993, and 1996, respectively.

From April 1996 to 2002, he was with the Graduate School of Engineering and Frontier Science, University of Tokyo, Tokyo, as an Assistant Professor. From 2002 to 2005, he was a Secretary for Policy to members of the House of Representatives (formerly Parliamentary Secretary for Land, Infrastructure, and Transport). Since 2005, he has been an Associate Professor with the Innovation and Joint Research Center, Shizuoka University, Hamamatsu, Japan. His research interests include the physics of microplasma and its applications to environmental protection.

Dr. Shimizu is a member of the Industry Applications Society of the Institute of Electrical Engineers of Japan (IEEJ) and the Institute of Electrostatics Japan.

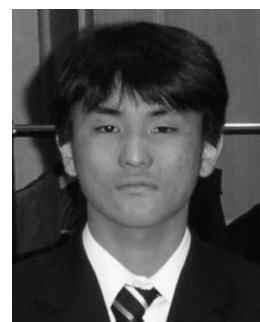

Tatsuya Ishii was born in Fuji, Japan, in 1984 $\mathrm{He}$ received the B.S. and M.S. degrees from Shizuoka University, Hamamatsu, in 2007 and 2009, respectively.

He has been part of a research team that examines the application and fundamental aspects of microplasma for environmental protection and microplasma generation by pulsed power. He is currently with Ricoh Company, Tokyo, Japan.

Mr. Ishii is a member of the Institute of Electrostatics Japan.

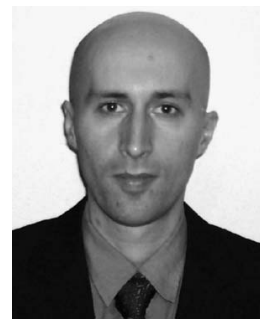

Marius Blajan (M'10) was born in Cluj-Napoca, Romania, in 1974. He received the B.S. and M.S degrees in electrical engineering from the Technical University of Cluj-Napoca, Cluj-Napoca, in 1997 and 2000, respectively, and the Ph.D. degree in electrical engineering jointly from the Technical University of Cluj-Napoca and the University of Poitiers, Poitiers, France, in 2006.

$\mathrm{He}$ was with the Electrical Company, Cluj, Romania, as an Engineer until October 2007. From November 2007 to March 2008, he was with the Power Distribution Division, EMFESZ, Romania, as an Engineer. Since April 2008, he has been a Postdoctoral Researcher with the Innovation and Joint Research Center, Shizuoka University, Hamamatsu, Japan. His research interests include the applications of nonthermal microplasma for NOx removal, indoor air purification, and sterilization.

Dr. Blajan is a member of the Institute of Electrostatics Japan and the Institute of Electrical Engineers of Japan. 